\title{
Metabolic and Hormonal Changes Induced by Hypodermoclysis of Glucose-Saline Solution in Elderly Patients
}

\author{
Véronique Dardaine, ${ }^{1}$ Marie-Ange Garrigue, ${ }^{2}$ Charles-Henri Rapin, ${ }^{3}$ and Thierry Constans ${ }^{1}$
}

\author{
'Ermitage Hospital, Tours, France. \\ ${ }^{2}$ Laboratory of Biochemistry, Bretonneau Hospital, Tours, France. \\ ${ }^{3}$ University Institute of Geriatrics, Geneva, Switzerland.
}

\begin{abstract}
Background. Hypodermoclysis, i.e., infusion of solutions into the subcutaneous tissues, is an alternative method for hydration. The aim of our study was to describe the metabolic changes induced by hypodermoclysis of a glucose-saline solution in elderly patients.
\end{abstract}

\begin{abstract}
Methods. Twelve experiments were conducted in a random cross-over study, intravenous infusion (IV) vs subcutaneous infusion (SC), in 6 hospitalized patients $(81.5 \pm 9.8$ years). The solution $(1000 \mathrm{~mL}$ of $5 \%$ glucose solution containing $4 \mathrm{~g} \mathrm{NaCl}$ ) was infused over 6 hours in fasted patients who remained in bed. Blood was sampled at $-10,0,30$, $60,90,120,180,240,300$, and 360 minutes for measurement of plasma concentrations of glucose, insulin, free fatty acids, and $\beta$-hydroxybutyrate. Plasma concentration of cortisol was analyzed only at T-10, T0, T180, and T360.

Results. The increases in glucose and insulin and the decrease in plasma concentrations of free fatty acids were lower with SC infusion than with IV infusion. The decrease in $\beta$-hydroxybutyrate plasma concentration was lower at T300 with SC infusion than with IV infusion. The decrease in cortisol did not differ with the route. Plasma concentrations of all compounds were similar at $\mathrm{T} 360$.
\end{abstract}

Conclusion. We conclude that hypodermoclysis of glucose-saline solution induced similar but smaller metabolic and hormonal changes than the IV infusion.

$\mathrm{H}$ YPODERMOCLYSIS is the infusion of solutions into the subcutaneous tissues. When drinking is insufficient and the intravenous route is undesirable, a situation frequently encountered in geriatric care, hypodermoclysis is an alternate method for hydration.

This procedure was widely used in the early fifties, particularly in pediatric medicine $(1,2)$. In 1951 accidents were attributed to misuse of the technique: Peripheral vascular collapse occurred, as a consequence of subcutaneous infusion of large amounts of electrolyte-free solutions, leading to a shift of extracellular electrolyte into the clysis site both in patients with shock (3) and those without (4-6). Subsequently, disuse of the technique gave way to the intravenous route. However, when correctly performed, hypodermoclysis provides undeniable advantages for the geriatric population (7-9) including ease of administration, no risk of venous thrombosis, low incidence of infection, and no need of a prolonged immobilization. Most importantly the technique does not require resident medical staff, avoiding potentially unneeded hospitalization of elderly patients.

Despite wide use of this technique for hydration, the effects of subcutaneous infusion of glucose-saline solutions on carbohydrate metabolism are to date unknown. The aim of our study was to describe the metabolic and hormonal changes induced by hypodermoclysis of glucose-saline solution in elderly patients.

\section{METHODS}

Subjects. - Six hospitalized elderly patients (5 women, 1 man), aged $81.5 \pm 9.8$ years (mean $\pm S D$, range: 69-93 years), were included in a random cross-over study comprising intravenous infusion (IV) vs subcutaneous infusion (SC). All the patients had been admitted at least 45 days before experiments for rehabilitation after a bone trauma which had required surgery. Patients with diabetes, obesity, fever, and hemostatic disturbance were excluded. The patients or their representatives gave informed consent, and our study was in accordance with the ethical standards of the Committee on Human Experimentation of our hospital.

Procedure. - Patients had fasted for 12 hours and remained in bed from the start $(8 \mathrm{a} . \mathrm{m}$.) to the end of each experiment ( 2 p.m.). The IV and SC infusions were separated by a 7-day period. The IV infusion was administered into a forearm vein. Hypodermoclysis was administered into the anterior wall of the abdomen. We used a 22-gauge steel needle to infuse $1000 \mathrm{~mL}$ of $5 \%$ glucose solution containing $4 \mathrm{~g} \mathrm{NaCl}$ over 6 hours.

A forearm vein was catheterized for blood sampling at 10 minutes before starting each experiment ( $\mathrm{T}-10)$, at the start of each experiment (T0), and 30,60, 90, 120, 180, 240, 300 and 360 minutes after the start of each experiment (T30, 
$\mathrm{T} 60, \mathrm{~T} 90, \mathrm{~T} 120, \mathrm{~T} 180, \mathrm{~T} 240, \mathrm{~T} 300, \mathrm{~T} 360)$. The catheter for IV infusion was inserted into a vein of the controlateral forearm (4 patients) or at least $10 \mathrm{~cm}$ above the punctured vein in the same forearm ( 2 patients).

The following plasma concentrations were measured: glucose (BioMérieux, Marcy-l'Etoile, France), insulin (Phadeseph Pharmacia, Upsala, Sweden), cortisol (Behring, DPC Los Angeles, USA), free fatty acids (Bœhringer, Mannheim, Germany), and $\beta$-hydroxybutyrate by the technique of Williamson et al. (10). Plasma concentration of cortisol was analyzed only at T-10, T0, T180 and T360.

The statistical analysis was performed by using a Wilcoxon test for paired values. Data are presented as mean $\pm S E M$.

\section{RESULTS}

The changes in plasma concentration of the different compounds measured are shown in Figure 1. Increases in glucose and insulin plasma concentrations were lower with SC infusion than with IV infusion, but these concentrations reached similar values at $\mathrm{T} 300$ and $\mathrm{T} 360$. The area under the curve (AUC) from T0 to T360 was lower in SC than in IV infusions (AUC glucose: $2,365 \pm 112$ vs $2,585 \pm 190$, mean $\pm S D, p<.03$ and AUC insulin: $25,136 \pm 12,180$ vs $37,548 \pm 25,566$, mean $\pm S D, p<.03$, SC vs IV infusions respectively). The decrease in plasma concentration of free fatty acids was lower (from T180 to T300) with SC infusion than with IV infusion. The decrease in $\beta$-hydroxybutyrate was less pronounced with SC infusion than with IV infusion but the difference was significant only at T300. The decrease in plasma concentration of cortisol did not differ whatever the route. Plasma concentrations were similar at T360 for all compounds tested.

\section{DisCUSSION}

Our study described the changes in plasma concentrations of the main compounds of carbohydrate metabolism when a glucose-saline solution was administered either by intravenous or subcutaneous route. Similar but smaller variations in plasma concentrations of glucose, free fatty acids, insulin, and cortisol occurred with SC infusion than with IV infusion. However, plasma concentrations reached similar values 5-6 hours after the start of the infusions. The decrease in plasma concentrations of $\beta$-hydroxybutyrate did not differ whatever the route.

The frequency of dehydration and undernutrition in elderly patients and the problems encountered for administering fluids, electrolytes, and nutriments in such patients, both by oral ingestion and intravenous infusion, emphasize the advantages of hypodermoclysis in routine practice. The classical method of hypodermoclysis involves the addition of hyaluronidase in the solution container and in the subcutaneous infusion site. Hyaluronidase is known to improve diffusion of a solution of $\mathrm{NaCl}$ in the subcutaneous tissue and to decrease the delay of appearance of $\mathrm{Na}$ in plasma (11). In the presence of hyaluronidase, the appearance in plasma of tritiated water infused subcutaneously is as rapid as appearance following IV infusion (12). The same effect has not been demonstrated for glucose infusion. In our study as in our practice (13), we did not use hyaluronidase.
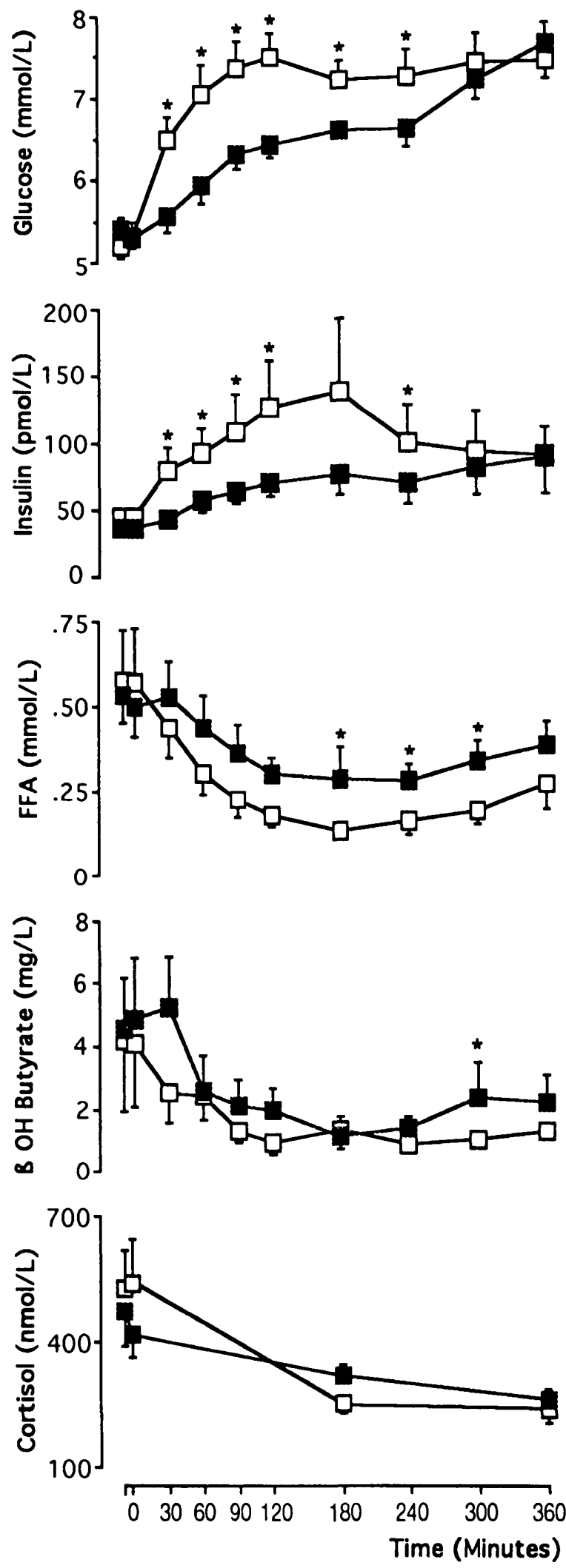

Figure 1. Changes in plasma concentrations of glucose, insulin, free fatty acids (FFA), $\beta$-hydroxybutyrate, and cortisol induced by IV infusion ( $\square$ ) or $\mathrm{SC}$ infusion ( $(\mathbf{)})$ of glucose-saline solution in 6 elderly patients. When not presented, SEM was smaller than symbol. Statistical analysis was performed using the Wilcoxon test for paired values. ${ }^{*} p<.05$. 
Therefore, our results suggest that glucose transfer from subcutaneous tissues to plasma is delayed. Our study design did not clarify whether the kind of molecule or the absence of hyaluronidase or both accounted for the differences observed. We did not evaluate changes in concentrations after infusion withdrawal. Prolonging the study beyond 6 hours would have led to much discomfort for our elderly patients.

We conclude that hypodermoclysis of a glucose-saline solution induced similar but smaller metabolic and hormonal changes than with IV infusion. Since hypodermoclysis is a useful method for hydration and nutrition in many clinical situations encountered in geriatric care and is without discomfort, this procedure needs further investigation and deserves more widespread use. Similar studies could be conducted in elderly patients to describe and to evaluate the effects of subcutaneous infusion of drugs and amino acids.

\section{ACKNOWLEDGMENTS}

We thank Dr. N. Mensi (Hôpital Cantonal Universitaire, Genève), Dr. C. Valat (Hôpital Bretonneau, CHU Tours), and Mrs. C. Jaquenod (Centre de Soins Continus, Genève) for their help with the measurements, and Mrs. D. Raine for her help with the English language.

Address correspondence to Dr. Véronique Dardaine, Hôpital de l'Ermitage, CHU de Tours, 2, allee Gaston Pagès, 37023 Tours Cedex, France.

\section{REFERENCES}

1. Hechter O, Dopkeen SK, Yudell MH. The clinical use of hyaluronidase in hypodermoclysis. J Pediatr 1947;30:645-56.
2. Schwartzman J. Hyaluronidase in pediatrics. J Pediatr 1949;34: 559-63.

3. Hall BD. Complications of hypodermoclysis (re-emphasis with a case presentation). J KY Med Assoc 1968;68:626-7.

4. Danowski TS, Winkler AW, Elkinton JR. Biochemical and hemodynamic changes following the subcutaneous injection of glucose solution. J Clin Invest 1947;26:887-91.

5. Abbott WE, Levey S, Foreman RC, Krieger H, Holden WD The danger of administering parenteral fluids by hypodermoclysis. Surgery 1952;32:305-15.

6. Butler JJ. Peripheral vascular collapse after the subcutaneous use of a hypertonic nonelectrolyte solution. N Engl J Med 1953;249:988-9.

7. Berger EY. Nutrition by hypodermoclysis. J Am Geriatr Soc 1984;32:199-203.

8. Simpson RG. Hyaluronidase in geriatric therapy. Practitioner 1977;219:361-3.

9. Schen RJ, Singer-Eldestein M. Subcutaneous infusons in the elderly. J Am Geriatr Soc 1981;29:583-5.

10. Williamson DH, Mellanby J, Krebs HA. Determination of D- $\beta$ hydroxybutyric acid and acetoacetic acid in blood. Biochem $J$ 1962;82:90-6.

11. Forbes GB, Deisher RW, Perley AM, Hartmann AF. Effect of hyaluronidase on the subcutaneous absorption of electrolytes in humans. Science 1950;111:177-9.

12. Lipschitz S, Campbell AJ, Roberts MS, Wanwimolruk S, McQueen EG, McQueen M, Firth LA. Subcutaneous fluid administration in elderly subjects: validation of an under-used technique. J Am Geriatr Soc 1991;39:6-9.

13. Constans T, Dutertre JP, Froge E. Hypodermoclysis in dehydrated elderly patients: local effects with and without hyaluronidase. J Pall Care 1991;7:10-2.

Received November 7, 1994

Accepted March 21, 1995 